\title{
Screening for asymptomatic coronary artery disease in patients with type 2 diabetes mellitus
}

Carlos Augusto F. Tavares', Bernardo Leo Wajchjenberg',

Carlos Rochitte', Antonio Carlos Lerario'

\begin{abstract}
Diabetes is a very frequent disease and it is estimated that its prevalence will continuously increase during the next two decades. The arteriosclerotic process in diabetic patients progresses earlier and more diffusely, and it is more accelerated in the diabetic patient than in the overall population. In diabetic subjects, acute myocardial infarction (AMI) and stroke are the leading causes of death, but the presence of arterial disease is not always detected before the development of the acute arterial event. Several times, AMI is asymptomatic or present nonspecific symptoms, and it is the initial form of presentation of coronary artery disease causing an important delay in initiating cardiovascular treatment in these patients. The purpose of this review article is to discuss how to screen and early diagnose the presence of coronary artery disease in asymptomatic diabetic patients, based on new available diagnostic resources. Currently, the most recommended technique used for screening coronary artery disease in these patients is myocardial perfusion scintigraphy or stress echocardiography because of greater sensitivity and specificity in relation to the exercise test. However, technological advances have enabled the development of new imaging diagnostic methods that are less invasive than conventional coronary angiography, and which gradually gain importance in the diagnosis of coronary artery disease as they show higher effectiveness with lower invasiveness and risk. Arch Endocrinol Metab. 2016;60(2):143-51
\end{abstract}

Keywords

Type 2 diabetes mellitus; coronary artery disease; tomography; X-ray/methods; atherosclerotic plate/classification
1 Instituto do Coração do Hospital das Clínicas da Faculdade de Medicina da Universidade de São Paulo (InCor/HC-FMUSP), Unidade de Coração e Diabetes e Departamento de Radiologia São Paulo, SP, Brasil

Correspondence to:

Carlos Augusto F. Tavares Núcleo de Diabetes, Departamento de Aterosclerose, Instituto do Coração Av. Dr. Enéas de Carvalho Aguiar, 44,

Bloco $B$, andar $A B$ 05403-000 - São Paulo, SP, Brasil fernandes-tavares@ig.com.br

Received on Feb/21/2014 Accepted on Mar/9/2016

DOI: 10.1590/2359-3997000000170

\section{INTRODUCTION}

$\mathrm{C}$ ardiovascular diseases are the leading causes of mortality of patients with DM2. Coronary artery disease (CAD) accounts for $75 \%$ of deaths and diabetes $(\mathrm{DM})$ is referred to as a secondary cause of death in approximately $50 \%$ of death certificates that have as a primary cause circulatory disease (1). Haffner and cols. estimate that the risk of death in a ten-year period in patients with $\mathrm{CAD}$ and $\mathrm{DM}$ exceeds $70 \%$ and, in his comments, suggest that the mortality rate from cardiovascular diseases in diabetic patients without acute myocardial infarction (AMI) is similar to without DM2 patients with anterior myocardial infarction (2). The association between diabetes and cardiovascular disease is demonstrated not only in patients with DM2, but also in earlier stages of the disease as impaired glucose tolerance or abnormal fasting glucose $(3,4)$.
The impact of diabetes on coronary heart disease can be clearly observed in several large case series studies, such as Whitehall, Paris Prospective Study, and the Helsinki Policeman Study, which demonstrated that patients with diabetes and impaired glucose tolerance have 2-4 times higher risk of developing cardiovascular disease than the non-diabetic patient population (5-7). Another feature observed in these subjects is high probability of presenting silent myocardial infarction. Non-specific or atypical symptoms, such as dyspnea, abdominal pain, and confusion were reported by $32 \%$ to $42 \%$ of diabetic patients with AMI compared with $6 \%$ to $15 \%$ of non-diabetic patients (8). Cardiovascular neuropathy, affecting myocardial sympathetic and parasympathetic fibers, is one of the mechanisms responsible for the increased incidence of silent infarctions in these patients. Postural hypotension and rest tachycar- 
dia include other symptoms of cardiovascular neuropathy that occur in diabetic patients with long-term poor glycemic control.

In diabetic patients, CAD is often detected at more advanced stages of the disease in comparison with the overall population, as in diabetic subjects, the arteriosclerotic process develops faster and earlier, and the patient remains longer asymptomatic for CAD. Atherosclerotic plaques in DM are usually characterized by their large volumes and lipid cores, which induce large remodeling rates in the affected vascular segment and have thin fibrous caps with intense inflammatory process that make them more vulnerable to rupture and may cause an acute coronary event. Diabetics also have more extensive, diffuse, and severe coronary artery involvement, which are factors associated with a worse prognosis. Necropsy studies in diabetic patients without evidence of CAD demonstrated that $50 \%$ and $75 \%$ of patients below and above 65 years old, respectively, had CAD in advanced stages (9).

Prospective, long-term clinical studies $(10,11)$ showed that adequate glycemic control associated with early treatment of other cardiovascular risk factors, such as obesity, hypertension and dyslipidemia are associated with lower morbidity and mortality in diabetic patients. Therefore, it is recommended that these patients are treated intensively at an early stage of the disease. However, as these conditions cannot be easily met in clinical practice due to the lack of patient compliance, limited access the required medications, and even due to the risk of cardiovascular acute events associated to hypoglycemia observed in patients undergoing intensive glycemic control. Therefore, the detection of CAD in asymptomatic patients can be valuable in raising the expectation and quality of life of these patients.

\section{HOW CAN ASYMPTOMATIC CAD BE DIAGNOSED IN DIABETIC PATIENTS?}

Several methods have recently been developed for the diagnosis and management of coronary lesions. Presently, conventional angiography remains as the gold standard for CAD diagnosis in patients with clinical suspicion or evidence of the disease, but it is controversial to use of this technique as a diagnostic routine method due to its invasiveness and the potential adverse effects of contrast injection, such as AMI, tachyarrhythmia, arterial obstruction, and bleeding. There is also the limited applicability as a routine technique for the diagnosis of asymptomatic patients due to its high technological complexity and cost. Moreover, in a recent retrospective study, Patel and cols., evaluating the results of the American College of Cardiology Data Registry in approximately 400,000 patients without known CAD who were undergoing elective catheterization, revealed the presence of obstructive CAD only in one third of the patients, suggesting that its routine use should be avoided, except when there is evidence indicated by other less aggressive diagnostic methods (12). The authors concluded that better strategies for risk stratification are needed to inform decisions and to increase the diagnostic yield of cardiac catheterization in routine clinical practice.

Therefore, we will discuss below other alternative strategies, including new, less invasive imaging techniques, that have been developed for the detection of $\mathrm{CAD}$.

\section{FUNCTIONAL INDIRECT TESTS THAT DETECT MYOCARDIAL ISCHEMIA}

The presence of myocardial ischemia can be evidenced by electrocardiographic changes through imaging techniques that assess abnormalities of myocardial perfusion using nuclear markers, such as computed tomography single photon emission tomography (SPECT), and by evaluation of changes in myocardial wall motion (echocardiography with pharmacological or physical stress). The functional tests that assess ischemia have better accuracy when performed during physical stress, such as exercising, or by using pharmacological agents including dobutamine, adenosine, and dipyridamole, which act indirectly by inhibiting the uptake and degradation of adenosine. Tests that use contrast markers, such as SPECT and cardiac magnetic resonance imaging, enable an integrated assessment of perfusion and cardiac function at rest and after stress. The next paragraphs describe the characteristics of some these routinely used diagnostic methods.

\section{Electrocardiogram}

The electrocardiogram (ECG) at rest can evidence prior coronary ischemia not recognized by as acute coronary syndrome by means of electrocardiographic changes, such as prominent $\mathrm{Q}$ wave and T-wave inversion. However, its sensitivity is very low. The continuous evaluation of the 24-hour ambulatory electrocardiogram can increase the diagnostic efficiency in detecting electrocardiographic signs of transient ischemia, but its sen- 
sitivity for CAD is still low (19\% to $62 \%)(13,14)$. The prevalence of silent myocardial ischemia in diabetic patients ranges from $35 \%$ to $58 \%$ in studies that used the ambulatory electrocardiogram $(15,16)$.

The use of the electrocardiogram during exercise increases the sensitivity of the method. In a meta-analysis (17) with approximately 24,000 patients who underwent conventional angiography and stress ECG, it was estimated that the electrocardiogram in effort showed sensitivity and specificity of $68 \%$ and $77 \%$, respectively, in CAD diagnosis. Sensitivity was higher in patients with $\mathrm{CAD}$ affecting three arteries. In an evaluation of exercise electrocardiography and coronary angiography for the identification of significant coronary stenosis conducted in 59 diabetic patients, sensitivity and specificity of exercise testing compared with conventional angiography were, respectively, $75 \%$ and $77 \%$ (18). The positive predictive value of the electrocardiogram per year in predicting CAD is estimated in $70 \%(19)$. In addition to the low sensitivity and specificity, this test is often inconclusive and inappropriate for diabetic patients (approximately 32\%) due to physical disability and vascular and neuropathic changes that make it difficult to reach the submaximal heart rate in the stress test.

\section{Myocardial perfusion imaging (SPECT - single photon emission computed tomography)}

Performed with the infusion of radioactive contrast (thallium or Sestamibi), this test yield multiple data, such as: location of lesion, extent of myocardial ischemia and left ventricular function, which can aid in determining the severity of the case. Exercise can be replaced by pharmacological stress (dipyridamole or adenosine). Scintigraphy has better sensitivity (80-90\%) and specificity $(75-90 \%)$ when compared with stress ECG in diabetics (18). Its main advantage is its high negative predictive value $(95 \%)$. In the overall population with $\mathrm{CV}$ risk factors or previous $\mathrm{CAD}$, the negative of result myocardial scintigraphy predicts less than $1 \%$ risk of death or myocardial infarction every year (20). In the asymptomatic diabetic population, the risk of cardiac events in five years is significantly higher with abnormal SPECT compared with absence of ischemia: respectively, $19.2 \%$ and $1.9 \%$ (21). Any myocardial ischemia involving areas greater than $10 \%$ of the left ventricle leads to coronary angiography (21). Currently SPECT is the most widely used test to assess silent myocardial ischemia in asymptomatic diabetic patients unable to perform adequate physical exercise testing.
The DIAD study (22) that screened asymptomatic diabetic patients for CAD by means of stress using adenosine showed myocardial perfusion deficit in $22 \%$ of 522 patients. In this study, the most important predictors of abnormal results were cardiac autonomic dysfunction, particularly the Valsalva maneuver $(\mathrm{OR}=$ $5.6)$, male gender $(\mathrm{OR}=2.5)$, and duration of diabetes $(\mathrm{OR}=5.2)$. In other study, Kharlip and cols. (23) evaluating the results of 116 myocardial scintigraphies of asymptomatic diabetic patients and observed perfusion deficit in $33.6 \%$ of patients, but the frequency of CAD that was confirmed by angiography was very low, only $11.2 \%$ for moderate or severe disease.

\section{Stress echocardiography}

Performed during physical exercise or pharmacological stress (dobutamine), it is in an alternative to detect silent myocardial ischemia in the overall population. This test detects motion abnormalities of the heart walls during stress, and provides information about the size and location of the ischemic area, as well as left ventricular function. In asymptomatic diabetic patients, the sensitivity and specificity of the method for CAD diagnosis are, respectively, $81 \%$ and $85 \%(24)$. A three-year follow-up of asymptomatic diabetic patients with negative stress echocardiograms demonstrated that the probability of a cardiovascular event was lower than $2 \%$ every year. In fact, this test has diagnostic and prognostic accuracy similar to SPECT, but with lower cost. However, it has some limitations, such as difficulty in interpreting the images in obese patients, and the inability of individuals to reach adequate heart rate during echocardiography, even when using vasoactive drugs, such as dobutamine and atropine.

A study performed to evaluate the effectiveness of screening, proposed by the ADA in 1998, assessed CAD in asymptomatic type 2 diabetics. Scognamiglio and cols., performing echocardiography with dipyridamole in 1899 asymptomatic type 2 diabetic patients below 60 years of age, observed that $59 \%$ of the tests were abnormal, but this elevated prevalence of ischemia was confirmed as significant CAD by conventional angiography only in 736 patients $(65 \%)$. This finding indicates the low specificity of the method for significant CAD diagnosis compared with conventional angiography (25). This discrepancy is probably related to differences in diagnostic strategies, when an indirect method that detects CAD by ischemia is compared with another method (angiography) that provides direct observation of anatomic coronary alterations. 
Imaging methods most commonly used to define the anatomic extent of atherosclerotic disease

The atherosclerotic process is responsible for the high morbidity and mortality of cardiovascular disease in diabetic patients. Therefore, there is growing appreciation and improvement of non-invasive imaging techniques to detect these lesions. In addition to accurate diagnosis and low risk of complications, these methods enable the analysis of atherosclerotic plaque features that provide information on the prognosis of the patients.

\section{Echo-Doppler ultrasound of the carotid}

The measurement of the average thickness of the intima-media thickness (IMT) of the carotid artery has been widely used as a marker of atherosclerotic disease. It consists of a non-invasive method that aids in the stratification of cardiovascular risk. The test is simple, fast and low cost, but the technique is not standardized. Carotid thickness may be assessed by ultrasonography in two different ways:

1. Multiple IMT measurements of the three main segments of the carotid: common carotid artery; carotid bifurcation; internal carotid artery bulb.

2. IMT computerized measurement of common carotid artery.

In type 2 diabetic subjects, IMT ranges from 0.71 to

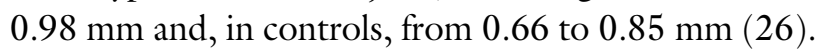
In several studies, IMT was determined by ultrasound as an independent and non-invasive risk predictor for coronary artery disease, stroke, and peripheral arterial disease (27-30). The European Society of Cardiology and the American Heart Association recommend measuring IMT by ultrasound to identify subclinical cases of cardiovascular disease (31).

However, carotid ultrasound has some limitations. There is a variability in the IMT measurements between observers, hindering the reproducibility of the data. Carotid regions with high susceptibility for atherosclerosis (bulb and bifurcation) are areas of difficult access to ultrasound since thickness of this vessel varies according to age, sex, blood pressure, and patient ethnicity. Therefore, it is not possible to determine a single reference value for the overall population.

\section{Calcium score (CS)}

Calcium score is a non-invasive method that detects the amount of calcium deposited in the coronary artery. Multidetector row computed tomography is employed in CS determination. Agatston and cols. (32) developed a coronary CS algorithm based on calcification density of the plaques, which is universally used to represent this index. CS is an estimate of the amount of calcified plaques in an individual, but it is not the total amount of corresponding plaques, or the percentage of luminal narrowing of coronary arteries. The MESA study, with 6,814 patients without known $\mathrm{CAD}$, concluded that the inclusion of the CS in the coronary disease risk factors improved risk stratification for CAD (33). The PREDICT study demonstrated a positive correlation between CS and the following parameters: age, male gender, diabetes duration, hypertension, and waist-to-hip ratio (34).

According Raggi and cols. (35), positive correlation between the risk of death and CS increase was observed both in DM and non-DM groups. However, there was a significant increase in mortality of DM group for similar CS in both populations [increase in $44 \%$ in the risk of death for each increase in calcium score $(\mathrm{p}=0.001)]$. However, in another study, Qu and cols. did not find a significant association between coronary events and CS in 269 individuals with DM followed up for six years (36). Furthermore, diabetic subjects with CS over 2.8 (considered low risk) presented four times higher values for coronary events, suggesting that the CS may underestimate the risk of CAD in diabetic patients (36). This fact is possibly explained by the different composition of the diabetic arteriosclerotic plaques in which lipid content, number of macrophages, inflammation substances, and quantity of thrombogenic substances are higher than those observed in the non-diabetic population, making DM patients more vulnerable to plaque rupture and coronary events. In the PREDICT study (34), designed to evaluate the validation CS as a cardiovascular event predictor in asymptomatic type 2 diabetic patients, there was a significant positive correlation $(\mathrm{p}<0.001)$ between the CS value and the probability of a cardiovascular events over time in the population studied.

\section{Intravascular ultrasound (IVUS)}

It is an invasive procedure that is performed during cardiac catheterization, in which a transducer is placed at the end of the coronary catheter and introduced into the artery. Using high frequency sound waves, it yields detailed images of the inner wall of the coronary artery. Angiography reveals a two-dimensional image of the coronary artery, but the IVUS shows a cross section of the lumen of the vessel and differentiates the three coronary layers, enabling a $360^{\circ}$ characterization 
of the arterial lumen. Three types of plaques are shown: hypoechoic (which indicates high amount of lipids); fibrous (which shows echogenicity similar to the adventitia layer, with high collagen and elastin content), and calcified (which shows hyperechoic components, producing acoustic shadowing of the vascular structures). The characterization of hypoechoic plaques has been proven to be useful in detecting vulnerable plaques. Lesions with increased risk of rupture and thrombosis are often associated to acute coronary syndromes.

Performing IVUS few weeks after heart transplantation in a cohort of 262 patients, Nissen observed high prevalence of coronary atherosclerosis in young patients between 20 and 30 years (37), despite the fact that conventional angiography was normal in $97 \%$ of these patients. The finding of high frequency of important atherosclerotic lesions in asymptomatic young patients by IVUS emphasize the early onset and the long latency period for the development of arteriosclerotic disease.

Since most of AMI are shown not to be associated with severe stenosis of the coronary arteries, but related to plaque rupture not visualized by conventional methods and that can be detected by new imaging technology that identifies plaque characteristics, makes these new imaging technique (IVUS) a potentially powerful and advanced diagnostic method for CAD detection. However, the relative weight of these two parameters of risk have not been adequately elucidated. In a recent publication of the CONFIRM study results (38) the importance of significant coronary stenosis was also demonstrated (obstruction $>50 \%$ of lumen) in worsening the prognosis of these patients. In this study, 10,110 CT angiography $(3,370$ examinations in diabetic patients and 6,740 patients without diabetes) were performed to assess CAD in individuals with CAD suspicion that were followed up for an average of 2.2 years. In the results, DM status and significant $\mathrm{CAD}$ were significantly associated with a nine-fold increase in mortality risk compared with individuals without diabetes and CAD, with statistical significance (HR 9.39 [4.8 to 18.2], p < 0.0001 ). In $62 \%$ of males and $50 \%$ females, myocardial infarction was the initial manifestation of CAD (39).

\section{Multislice computed tomography (MSCT)}

MSCT is a relatively simple and fast method that presents a growing technological evolution. Currently, the CT scan obtained by 320-detector row scanners is considered as the standard for clinical use. It is a non-inva- sive method to visualize the coronary artery, detect the degree of stenosis caused by the deposition of atheroma plaques in this vessel, and determine the coronary calcium score. It also provides information about the composition of the plaques, the presence of remodeling and extension of coronary lesions, as seen in Figures 1 and 2.

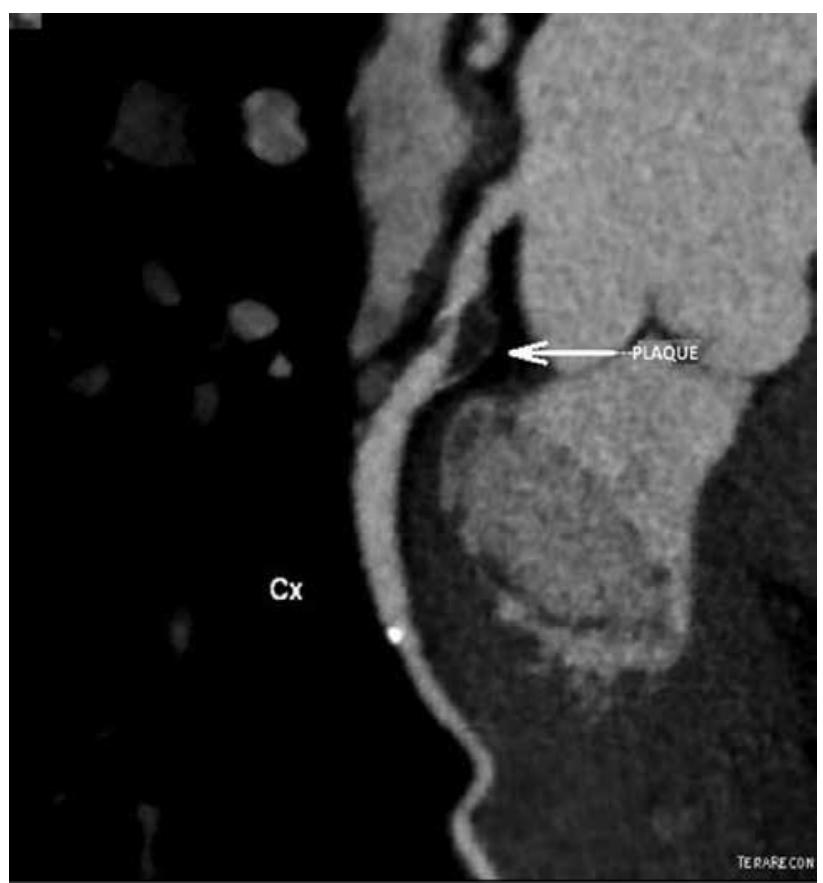

Figure 1. Atherosclerotic plaque vulnerable in circumflex branch of coronary with large vascular remodeling in the affected segment (image courtesy of PhD Carlos Rochitte.)

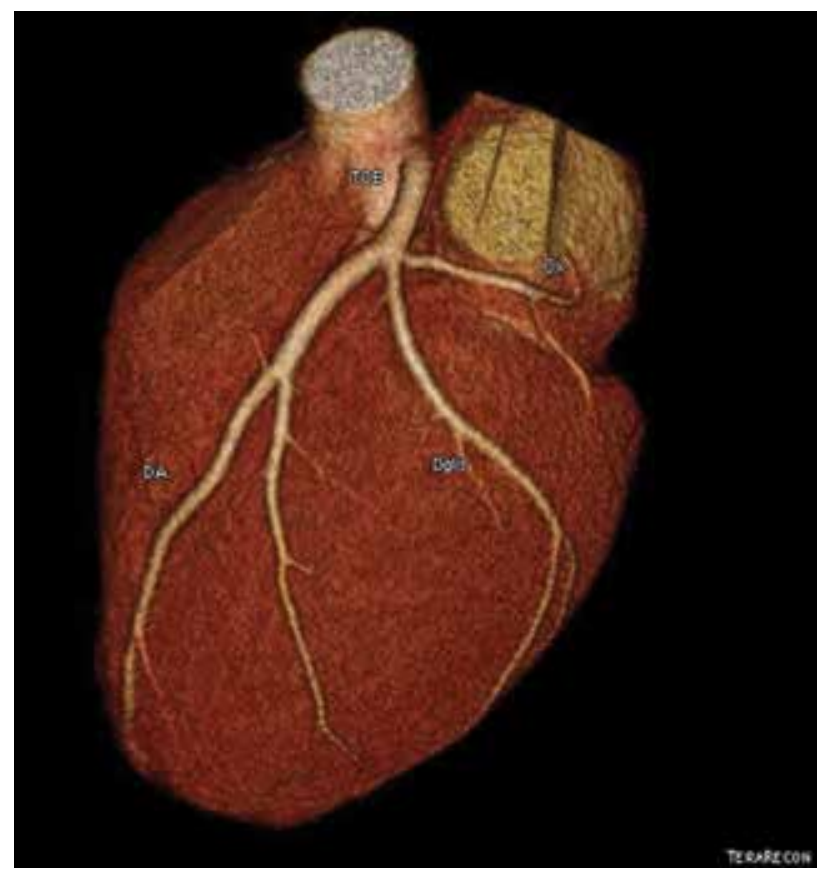

Figure 2. CT angiography (image courtesy of PhD Carlos Rochitte). 
When compared to invasive angiography, MSTC with 64 rows of detectors, demonstrated high sensitivity (between $83 \%$ to $99 \%$ ), specificity (93\% to $98 \%$ ) and negative predictive value (99\%) in a total of 542 patients in 9 studies $(40,41)$. A multicenter study with 291 patients with CAD suspicion evaluated the accuracy of 64-row MSCT compared with conventional arteriography and showed arterial occlusion in $50 \%$ of patients in both methods (42). MSCT enables the classification of different types of plates. The plaques can be classified according to the calcium composition in non-calcified, mixed, and calcified. In acute coronary events, a predominance of the non-calcified and mixed plaques was observed (43). A study comparing the ability of MSCT to detect calcified and non-calcified plaques in comparison to IVUS, Achenbach and cols. evaluating 22 patients without significant coronary stenosis observed by MSTC the diagnosis for calcified plaque: $94 \%$ sensitivity and specificity and non calcified plaque: a sensitivity of $78 \%$ and specificity of $87 \%$. The authors concluded that MSTC showed less accurate detection of non-calcified plaques compared with IVUS, and underestimated the volume of plaques by segment (44).

Motoyama (45), comparing the characteristics of the plaques associated with acute events in 38 patients with arteriosclerotic lesions in 33 patients with stable angina using MSTC, demonstrated a significant correlation of the plaques with rupture and acute coronary events when the presence of the following plaque features were present: 1) considerable vascular remodeling; 2) non-calcified plaques with low attenuation (density $<30 \mathrm{HU}$ ); and 3) spotty calcification of the plaques. Recently, in another study using MSCT (46), the same investigators followed 1,059 patients for $27 \pm 10$ months and demonstrated, in 45 patients with CAD plaques that showed simultaneously two traits instability (positive remodeling and low attenuation of atherosclerotic plaques), higher incidence of acute coronary events compared with individuals with plaques that did not show these two characteristics.

The limitations to the use of MSCT are related to patient exposure to radiation (MSCT 320: 1-2 MSV), lower accuracy in the presence of calcification, severe artifacts associated with cardiac motion, low applicability in the cases of arrhythmias and severe obesity, use of iodinated contrast with nephrotoxic potential, and high cost for routine clinical use. Despite the fact that morphological assessment of atherosclerotic pla- que and degree of coronary stenosis by IVUS and conventional coronary angiography, respectively, continue to be considered as gold standard methods for CAD, MSCT is presented as a very useful alternative, as it is a non-invasive method and, therefore, has low risk of complications, making it potentially recommended.

\section{What is the best diagnostic method for the detection of cad in patients with diabetes?}

The results of the studies evaluating the use of various diagnostic methods for $\mathrm{CAD}$ have shown a prevalence of positive findings for coronary alterations higher than $25 \%$ in asymptomatic diabetic patients, revealing fundamental importance of the identification of patients with established atherosclerotic disease $(22,23)$.

However, some issues still remain controversial: 1. What would be the best test to be carried out?; 2 . Is there a subgroup of diabetic patients that are more prone to $\mathrm{CAD}$ ?; 3 . What is the ideal time for testing? All these questions need to be answered in order to optimize their cost-benefit ratio and preventing the use of sophisticated imaging methods of less applicability for routine clinical use in the screening of diabetic patients for coronary disease. However, if it is considered that virtually all diabetic patients have an intrinsic increased cardiovascular risk, so the indication of screening would be based in expectation and quality of life of patients.

Diabetic patients with multiple risk factors associated with metabolic syndrome, especially with inadequate glycemic control for longer periods should be evaluated. In these patients, the use of imaging techniques, especially CT angiography proved to be most appropriate, sensitive, specific, and safe compared with other functional techniques. The electrocardiogram at rest and in effort demonstrate relatively low sensitivity and specificity for the diagnosis of coronary ischemia in diabetic patients. The diagnostic sensitivity of myocardial perfusion scintigraphy and stress echocardiography show good and fairly similar results, but they are functional tests that assess ischemia triggered by stress and not the anatomy of the coronary arteries..

Recently, there has been increasing interest on the use of imaging techniques that directly detect arteriosclerosis, especially MSCT. CS is a method that adds prognostic value to $\mathrm{CAD}$ prediction, but results cannot be assessed alone. MSCT presented the following advantages: high sensitivity and specificity in the detec- 
tion of obstructive changes, characterization of atherosclerotic plaques, good predictive power and being a non-invasive technique. It has, as limiting factors to its routine use, its high cost, patient exposure to radiation, and especially the use of potentially nephrotoxic iodinated contrast.

Therefore, the indication and choice of one of several methods available for the diagnosis of asymptomatic CAD still depends on major technological advances and mainly on conducting further studies to determine the role of these new methods in early diagnosis screening of asymptomatic diabetic patients. The table at the end of the article is a summary of this review, showing the most important features of each diagnostic method discussed above( Table 1).

\section{Which diabetic patient should undergo screening for CAD?}

In principle, all patients with diabetes, especially those with poor, long-term glycemic control are at increased cardiovascular risk. However, the presence of specific risk factors such as not clinically manifest macroangiopathy, changes in electrocardiography at rest, micro-macroalbuminuria, cardiac autonomic neuropathy, and longer duration of diabetes, premature family history of CAD (men $<55$ years and women $<65$ years old), obesity, dyslipidemia, smoking, and high blood pressure, increase the probability for the patient deve- lop an acute cardiovascular event regardless of the presence of coronary symptoms.

However, since an overall analysis of available studies do not demonstrate fully conclusive results or have limited applicability, the American Diabetes Association does not recommend routine screening for CAD in asymptomatic diabetic patients for believing that survival does not increase in relation to the intensive clinical treatment of cardiovascular risk factors. Therefore, these methods are reserved only for patients with typical or atypical cardiac symptoms or abnormal ECG at rest (47).

In people with diabetes, the diagnosis of coronary artery disease based on clinical symptomatology has lower reliability. Coronary atherosclerotic plaques develop early, in a more diffuse and accelerated rate when compared with the overall population, therefore a more careful screening for CAD in diabetic patients is justified to improve patient survival.

\section{Commentaries and conclusions from the authors}

Diagnosis of CAD is usually not routinely performed by general practitioners and endocrinologists in diabetic subjects in our country, except when this disease or signs symptoms of coronary ischemia is suspected. In these cases, resting electrocardiogram or after exercise are the most frequently requested test. Due to the high costs, lack of availability, and difficulty to set appointments

Table 1. Summary of the characteristics of the most important methods for diagnosing CAD in DM 2 patients

\begin{tabular}{|c|c|c|c|c|c|c|c|c|}
\hline Diagnostic method & Technique & Contrast & Cost & Sens. & Spec. & Complications & Advantages & Disadvantages \\
\hline Conventional angiography & Invasive & Yes & High & High & High & $\begin{array}{c}\text { AMl, arrhythmias, } \\
\text { bleeding, infections, } \\
\text { stroke }\end{array}$ & Gold standard & Invasive \\
\hline Ergometric test & Noninvasive & No & Low & Low & Low & $\begin{array}{l}\text { Rare: arrhythmias, } \\
\text { AMl }\end{array}$ & Low cost & Inconclusive results \\
\hline Myocardial scintigraphy & Noninvasive & Yes & High & High & High & Rare & $\begin{array}{l}\text { Physical stress or } \\
\text { pharmacological }\end{array}$ & $\begin{array}{l}\text { Functional test }< \\
\text { sens I specif MSTC }\end{array}$ \\
\hline Stress echocardiography & Noninvasive & No & Low & High & High & Rare: arrhythmias & Low cost & $\begin{array}{c}\text { Difficulties: obese } \\
\text { achieve submax HR }\end{array}$ \\
\hline Carotid Doppler ultrasonography & Noninvasive & No & Low & Low & Low & No & $\begin{array}{l}\text { Low cost } \\
\text { fast }\end{array}$ & $\begin{array}{l}\text { Indirect method No } \\
\text { standard }\end{array}$ \\
\hline Calcium Score & Noninvasive & Yes & High & Low & Low & Rare & Noninvasive & $\begin{array}{l}\text { Indirect method does } \\
\text { not show percentage } \\
\text { obstruction }\end{array}$ \\
\hline Intravascular ultrasound (IVUS) & Invasive & No & High & High & High & $\begin{array}{c}\text { AMl, arrhythmias, } \\
\text { bleeding, infections, } \\
\text { stroke }\end{array}$ & $\begin{array}{c}\text { Gold standard } \\
\text { characterize plates }\end{array}$ & Invasive \\
\hline $\begin{array}{l}\text { Angiotomography coronary } \\
\text { (MSTC) }\end{array}$ & Noninvasive & Yes & High & High & High & nephrotoxicity & $\begin{array}{l}\text { Sens/Specif slightly } \\
\text { lower of angiography }\end{array}$ & $\begin{array}{l}\text { Not applicable in } \\
\text { obesity and } \\
\text { arrhythmias; cost }\end{array}$ \\
\hline
\end{tabular}


with new imaging tools, only few of patients undergo testing with more advanced imaging technologies. Currently, the most recommended technique for CAD screening in these selected patients is myocardial perfusion scintigraphy or stress echocardiography because they have greater sensitivity and specificity in relation to the exercise test. Furthermore, besides the economic barrier, invasiveness, high radiation exposure, and potential side effects associated to many of these techniques also limit the wider use of these modern technologies in early detection of CAD. However, the fast and continuing observed advances in efficacy and safety, increased ease of use, more efficiency and safety, and lower costs of these new imaging methods may enable their wider use as diagnostic tools for CAD in the near future.

Disclosure: no potential conflict of interest relevant to this article was reported.

\section{REFERENCES}

1. Bonow RO, Bohannon N, HazzardW. Risk stratification in coronary artery disease and special population. Am J Med. 1996;101:417S22S.

2. Haffner SM, Lehto S, RönnemaaT, Pyörälä K, Laakso M. Mortality from coronary heart disease in subjects with type 2 diabetes and in nondiabetic subjects with and without prior myocardial infarction. N Engl J Med. 1998;339:229-34.

3. Diabetes Association, Clinical Practice Recommendations: 2006 Diagnosis and Classification of Diabetes Mellitus. Diabetes Care. 2006;29:S43-8.

4. Alexander CM, Landsman PB, Teutsch SM. Diabetes mellitus, impaired fasting glucose, atherosclerotic risk factors, prevalence and coronary hearth disease. Am J Cardiol. 2000;86:897-902.

5. Fuller JH, Shipley MJ, Rose G, Jarrett RJ, Keen H. Coronary-heartdisease risk and impaired glucose tolerance. The Whitehall study. Lancet. 1980;1(8183):1373-6.

6. Balkau B, Shipley M, Jarrett RJ, Pyörälä K, Pyörälä M, Forhan A, et al. High blood glucose concentration is a risk factor for mortality in middle-aged nondiabetic men. 20-year follow-up in the Whitehall Study, the Paris Prospective Study, and the Helsinki Policemen Study. Diabetes Care. 1998;21(3):360-7.

7. Pyörälä $M$, Miettinen $H$, Laakso $M$, Pyörälä K. Hyperinsulinemia predicts coronary heart disease risk in healthy middle-aged men: the 22-year follow-up results of the Helsinki Policemen Study. Circulation. 1998;98(5):398-404.

8. Barthelemy O, Lê Feuvre C, Timsit J. Silent myocardial ischemia screening in patients with diabetes mellitus. Arq Bras Endocrinol Metab. 2007;51(2):285-93.

9. GorayaTY, Leibson CL, Palumbo PJ, Weston SA, Killian JM, Pfeifer EA, et al. Coronary atherosclerosis in diabetes mellitus: a population-based autopsy study. J Am Coll Cardiol. 2002;40(5):946-53.

10. Gaede P, Vedel P, Parving $H$, Pedersen O. Intensified multifactorial intervention in patients with type 2 diabetes mellitus and microalbuminuria: The STENO type 2 randomised study. Lancet. 1999;353:617-22.

11. Schatz H. [2008--The year of the big studies about the therapy of type-2-diabetes. ACCORD, ADVANCE, VADT, and the UKPDS 10-year follow-up data]. MMW Fortschr Med. 2009;151(12):42-3.
12. Patel MR, Peterson ED, Dai D, Brennan JM, Redberg RF, Anderson $\mathrm{HV}$, et al. Low diagnostic yield of elective coronary angiography. N Engl J Med. 2010;362(10):886-95.

13. Djaberi R, Beishuizen E, Pereira A, Rabelink T, Smit J, Tamsma J, et al. Non-invasive cardiac imaging techniques and vascular tools for the assessment of cardiovascular disease in type 2 diabetes mellitus. Diabetologia. 2008;51(9):1581-93.

14. Crawford MH, Mendoza CA, Orouke RA, White DH, Boucher CA, Gorwin J. Limitations of continuous ambulatory electrocardiogram monitoring for detecting coronary artery disease. Ann Intern Med. 1978;89(1):1-5.

15. Chiariello M, Indolfi C, Cotecchi MR, Sifola C, Romano M, Condorelli M. Asymptomatic transient ST changes during ambulatory ECG monitoring in diabetic patients. Am Heart J. 1985;110(3):52934.

16. Aronow WS, Mercando AD, Epstein S. Prevalence of silent myocardial ischemia detected by 24-hour ambulatory electrocardiography, and its association with new coronary events at 40-month follow-up in elderly diabetic and nondiabetic patients with coronary artery disease. Am J Cardiol. 1992;69(5):555-6.

17. Gianrossi R, Detrano R, Mulvihill D, Lehmann K, Dubach P, Colombo $A$, et al. Exercise-induced ST depression in the diagnosis of coronary artery disease. A meta-analysis. Circulation. 1989;80(1):87-98.

18. Paillole C, Ruiz J, Juliard JM, Leblanc H, Gourgon R, Passa P. Detection of coronary artery disease in diabetic patients. Diabetologia. 1995;38:726-31.

19. Bacci S, Villella M, Villella A, Langialonga T, Grilli M, Rauseo A, et al. Screening for silent myocardial ischaemia in type 2 diabetic patients with additional atherogenic risk factors: applicability and accuracy of the exercise stress test. Eur $\mathrm{J}$ Endocrinol. 2002;147(5):649-54.

20. Vanzetto G, Ormezzano O, Fagret D, Comet M, Denis B, Machecourt J. Long-term additive prognostic value of thallium-201 myocardial perfusion imaging over clinical and exercise stress test in low to intermediate risk patients: study in 1137 patients with 6-year follow-up. Circulation. 1999;100(14):1521-7.

21. Faglia E, Favales F, Calia P, Paleari F, Segalini G, Gamba PL, et al. Cardiac events in 735 type 2 diabetic patients who underwent screening for unknown asymptomatic coronary heart disease: 5-year follow-up report from the Milan Study on Atherosclerosis and Diabetes (MiSAD). Diabetes Care. 2002;25(11):2032-6.

22. Wackers FJ, Young LH, Inzucchi SE, Chyun DA, Davey JA, Barret EJ, et al. Detection of silent myocardial ischemia in asymptomatic diabetic subjects: the DIAD study. Diabetes Care. 2004;27(8):1954-61.

23. Kharlip J, Naglieri R, Mitchell BD, Ryan KA, DonnerTW. Screening for silent coronary heart disease in type 2 diabetes: clinical application of American Diabetes Association guidelines. Diabetes Care. 2006;29(3):692-4.

24. Elhendy A, van Domburg RT, Poldermans D, Bax JJ, Nierop PR, Geleijnse ML, et al. Safety and feasibility of dobutamine-atropine stress echocardiography for the diagnosis of coronary artery disease in diabetic patients unable to perform an exercise stress test. Diabetes Care. 1998;21(11):1797-802.

25. Scognamiglio R, Negut C, Ramondo A, Tiengo A, Avogaro A. Detection of coronary artery disease in asymptomatic patients with type 2 diabetes mellitus. J Am Coll Cardiol. 2006;47(1):65-71.

26. Lee CD, Folsom AR, Pankow JS, Brancati FL; Atherosclerosis risk in communities (ARIC) study investigators. Cardiovascular events in diabetic and nondiabetic adults with or without history of myocardial infarction. Circulation. 2004;109:855-60.

27. Chambless LE, Heiss G, Folsom AR, Rosamond W, Szklo M, Sharrett $A R$, et al. Association of coronary heart disease incidence with carotid arterial wall thickness and major risk factors: the Ath- 
erosclerosis Risk in Communities (ARIC) Study 1987-1993. Am J Epidemiol. 1997;146:483-94.

28. Bots ML, Hoes AW, Koudstaal PJ, Hofman A, Grobbee DE. Common carotid intima-media thickness and risk of stroke and myocardial infarction: the Rotterdam Study. Circulation. 1997;96(5):1432-7.

29. Touboul PJ, Hernández-Hernández R, Küçükoğlu S, Woo KS, Vicaut E, Labreuche J, et al.; PARC-AALA Investigators. Carotid artery intima media thickness, plaque and Framingham cardiovascular score in Asia, Africa/Middle East and Latin America: the PARC-AALA study. Int J Cardiovasc Imaging. 2007;23(5):557-67.

30. Cuspidi C, Lonati L, Macca G, Sampieri L, Fusi V, Severgnini B, et al. Cardiovascular risk stratification in hypertensive patients: impact of echocardiography and carotid ultrasonography. J Hypertens. 2001;19(3):375-80.

31. Greenland $P, A$, brams J, Aurigemma GP, Bond MG, Clark LT, Criqui $\mathrm{MH}$, et al. Prevention Conference V: Beyond secondary prevention: identifying the high-risk patient for primary prevention: noninvasive tests of atherosclerotic burden: Writing Group III. Circulation. 2000;101(1):E16-22.

32. Agatston AS, Janowitz WR, Hildner FJ, Zusmer NR, Viamonte M $\mathrm{Jr}$, Detrano R. Quantification of coronary artery calcium using ultrafast computed tomography. J Am Coll Cardiol. 1990;15(4):82732.

33. Bild DE, Bluemke DA, Burke GL, Detrano R, Diez Roux AV, Folsom AR, et al. Multi-Ethnic Study of Atherosclerosis: objectives and design. Am J Epidemiol. 2002;156(9):871-81.

34. Elkeles RS, Godsland IF, Feher MD, Rubens MB, Roughton M, Nugara F, et al.; PREDICT Study Group. Coronary calcium measurement improves prediction of cardiovascular events in asymptomatic patients with type 2 diabetes: the PREDICT study. Eur Heart J. 2008;29(18):2244-51.

35. Raggi P, Shaw LJ, Berman DS, Callister TQ. Prognostic value of coronary artery calcium screening in subjects with and without diabetes. J Am Coll Cardiol. 2004;43(9):1663-9.

36. Qu W, LeTT, Azen SP, Xiang M, Wong ND, Doherty TM, et al. Value of coronary artery calcium scanning by computed tomography for predicting coronary heart disease in diabetic subjects. Diabetes Care. 2003;26(3):905-10.

37. Nissen SE. Who is at risk for atherosclerotic disease? Lessons from intravascular ultrasound. Am J Med. 2002;112 Suppl $8 \mathrm{~A}: 27 \mathrm{~S}-33 \mathrm{~S}$
38. Rana JS, Dunning A, Achenbach S, Al-Mallah M, Budoff MJ, Cademartiri $F$, et al. Differences in prevalence, extent, severity, and prognosis of coronary artery disease among patients with and without diabetes undergoing coronary computed tomography angiography: results from 10,110 individuals from the CONFIRM (COronary CT Angiography EvaluatioN For Clinical Outcomes): an InteRnational Multicenter Registry. Diabetes Care. 2012;35(8):1787-94.

39. Little WC, Constantinescu M, Applegate RJ, Kutcher MA, Burrows MT, Kahl FR, et al. Can coronary angiography predict the site of a subsequent myocardial infarction in patients with mild-to-moderate coronary artery disease? Circulation. 1988;78(5 Pt 1):1157-66.

40. Anand DV, Lim E, Lahiri A, Bax JJ. The role of non-invasive imaging in the risk stratification in assinptomatic diabetic subjects. European Heart J. 2006;27:905-12.

41. Burgstahler C, BeckT, Reimann A, Kuettner A, Kopp A, Heuschmid $M$, et al. Diagnostic accuracy of multislice computed tomography for the detection of coronary artery disease in diabetic patients. $J$ Diabetes Complications. 2007;21(2):69-74.

42. Miller JM, Rochite CE, Dewey M, Zadeh AA, Nimuma H, Gottlieb I, et al. Diagnostic performance of coronary angiography by 64 -row CT. N Engl J Med. 2008;359(22):2324-36.

43. Hoffmann U, Moselewski F, Nieman K, Jang IK, Ferencik M, Rahman AM, et al. Noninvasive assessment of plaque morphology and composition in culprit and stable lesions in acute coronary syndrome and stable lesions in stable angina by multidetector computed tomography. J Am Coll Cardiol. 2006;47(8):1655-62.

44. Achenbach S, Moselewski, Robers D, Ferencik M, Hoffman U, MacNeill B, et al. Detection of calcified and noncalcified coronary atherosclerotic plaque by contrast-enhanced, submillimeter multidetector spiral computed tomography: a segmentbased comparison with intravascular ultrasound. Circulation. 2004;109(1):14-7.

45. Motoyama S, Kondo T, Sarai M, Sugiura A, Harigaya H, Sato T, et al. Multislice computed tomographic characteristics of coronary lesions in acute coronary syndromes. J Am Coll Cardiol. 2007;50(4):319-26.

46. Motoyama S, Sarai M, Harigaya H, Anno H, Inoue K, Hara T, et al. Computed tomographic angiography characteristics of atherosclerotic plaques subsequently resulting in acute coronary syndrome. J Am Coll Cardiol. 2009;54(1):49-57.

47. Standards of Medical Care in Diabetes-2011: American Diabetes Association. Available from: care.diabetesjournals.org. Access on: Aug. 2014. 